\title{
ICE1: a regulator of cold-induced transcriptome and freezing tolerance in Arabidopsis
}

\author{
Viswanathan Chinnusamy, Masaru Ohta, Siddhartha Kanrar, Byeong-ha Lee, Xuhui Hong, \\ Manu Agarwal, and Jian-Kang $\mathrm{Zhu}^{1}$ \\ Department of Plant Sciences, University of Arizona, Tucson, Arizona 85721, USA
}

Cold temperatures trigger the expression of the CBF family of transcription factors, which in turn activate many downstream genes that confer chilling and freezing tolerance to plants. We report here the identification of ICE1 (inducer of $\underline{C} B F$ expression 1), an upstream transcription factor that regulates the transcription of $C B F$ genes in the cold. An Arabidopsis ice1 mutant was isolated in a screen for mutations that impair cold-induced transcription of a $C B F 3$ promoter-luciferase reporter gene. The ice1 mutation blocks the expression of $C B F 3$ and decreases the expression of many genes downstream of $C B F$, which leads to a significant reduction in plant chilling and freezing tolerance. ICE1 encodes a MYC-like bHLH transcriptional activator. ICE1 binds specifically to the MYC recognition sequences in the CBF3 promoter. ICE1 is expressed constitutively, and its overexpression in wild-type plants enhances the expression of the CBF regulon in the cold and improves freezing tolerance of the transgenic plants.

[Keywords: Cold signaling; freezing tolerance; bHLH protein; CBF regulation; transcriptome] Supplemental material is available at http://www.genesdev.org.

Received January 23, 2003; revised version accepted February 14, 2003.

Cold is an environmental factor that limits the geographical distribution and growing season of many plant species, and it often adversely affects crop quality and productivity (Thomashow 1999). Most temperate plants can acquire tolerance to freezing temperatures by a prior exposure to low nonfreezing temperatures, a process known as cold acclimation (Guy 1990; Hughes and Dunn 1996; Browse and Xin 2001). Plants of tropical and subtropical origins are sensitive to chilling temperatures $\left(0^{\circ} \mathrm{C}-10^{\circ} \mathrm{C}\right)$ and are incapable of cold acclimation. Many studies have suggested that cold-regulated gene expression is critical in plants for both chilling tolerance (Gong et al. 2002; Hsieh et al. 2002) and cold acclimation (Knight et al. 1999; Thomashow 1999; Tahtiharju and Palva 2001). Cold-responsive genes encode a diverse array of proteins such as enzymes involved in respiration and metabolism of carbohydrates, lipids, phenylpropanoids and antioxidants; molecular chaperones, antifreeze proteins, and others with a presumed function in tolerance to the dehydration caused by freezing (Guy 1990; Thomashow 1999; Mohapatra et al. 1989).

Many of the cold and dehydration responsive genes have in their promoters one or several copies of the DRE/

${ }^{1}$ Corresponding author.

E-MAIL jkzhu@ag.arizona.edu; FAX (520) 621-7186.

Article published online ahead of print. Article and publication date are at http://www.genesdev.org/cgi/doi/10.1101/gad.1077503.
CRT cis-element, which has the core sequence, CCGAC (Yamaguchi-Shinozaki and Shinozaki 1994; Stockinger et al. 1997). A family of transcription factors known as CBFs or DREB1s binds to this element and activates transcription of the downstream cold and dehydrationresponsive genes (Stockinger et al. 1997; Liu et al. 1998). Interestingly, the $C B F / D R E B 1$ genes are themselves induced by low temperatures. This induction is transient and precedes that of the downstream genes with the DRE/CRT cis-element (Thomashow 1999). Therefore, there is a transcriptional cascade leading to the expression of the DRE/CRT class of genes under cold stress. Ectopic expression of $C B F s / D R E B 1 s$ in plants turns on downstream cold-responsive genes even at warm temperatures and confers improved freezing tolerance (Jagglo-Ottosen et al. 1998; Liu et al. 1998).

Since $C B F$ transcripts begin accumulating within 15 min of plants' exposure to cold, Gilmour et al. (1998) proposed that there is a transcription factor already present in the cell at normal growth temperature that recognizes the $C B F$ promoters and induces $C B F$ expression upon exposure to cold stress. Gilmour et al. (1998) named the unknown activator(s) "ICE" (inducer of $\underline{\mathrm{CBF}}$ expression) protein(s) and hypothesized that upon exposing a plant to cold, modification of either ICE or an associated protein would allow ICE to bind to $C B F$ promoters and activate $C B F$ transcription.

Genetic analysis in Arabidopsis plants expressing the 
firefly luciferase reporter gene driven by the $C R T / D R E$ element-containing $R D 29 A$ promoter (Ishitani et al. 1997) has identified several mutants with deregulated cold-responsive gene expression. The hos1 (high expression of osmotically responsive genes) mutant shows an enhanced cold-induction of CBFs and their downstream cold responsive genes (Ishitani et al. 1998). HOS1 encodes a RING finger protein that is present in the cytoplasm at normal growth temperatures, but accumulates in the nucleus upon cold treatment. Since many RINGfinger proteins are known to serve as ubiquitin E3 ligases, HOS1 has been proposed to function by targeting certain positive regulator(s) of $C B F$ s for ubiquitination and degradation (Lee et al. 2001). The transcription of $C B F$ genes is also under feedback repression by its own gene product or its downstream target gene products. This was revealed by studies on the los 1 mutant that is defective in the translational elongation factor 2 gene (Guo et al. 2002). The los 1 mutation blocks cold induction of genes with the $C R T / D R E$ element, but causes superinduction of the $C B F$ genes. It was shown that protein synthesis in los1 mutant plants is disrupted specifically in the cold. Therefore, cold-induced CBF transcripts cannot be translated to activate downstream genes, and feedback repression cannot occur, leading to superinduction of CBF transcripts (Guo et al. 2002).

Another Arabidopsis mutation, los2, also impairs cold induction of $C R T / D R E$ element-containing genes (Lee et al. 2002). LOS2 encodes a bifunctional enolase that can bind to the promoter of $Z A T 10$, a zinc finger transcriptional repressor. ZAT10 expression is rapidly and transiently induced by cold in the wild type, and this induc- tion is stronger and more sustained in the los 2 mutant. Therefore, LOS2 may control the expression of delayed cold response genes via transcriptional repression of ZAT10 (Lee et al. 2002). The Arabidopsis LOS4 locus is involved in the accumulation of $C B F$ transcripts under cold treatment (Gong et al. 2002). los4-1 mutant plants are sensitive to chilling stress, and the chilling sensitivity can be rescued by ectopic expression of CBF3 (Gong et al. 2002). LOS4 encodes a DEAD-box RNA helicase, suggesting that RNA metabolism may be involved in cold responses.

We carried out a genetic screen (Chinnusamy et al. 2002) to identify cold signaling components upstream of the CBF proteins. A cold-responsive bioluminescent Arabidopsis plant was engineered by expressing the firefly luciferase $(L U C)$ coding sequence under the control of the CBF3 promoter. Homozygous CBF3-LUC plants were chemically mutagenized and mutants with altered cold-induced CBF3-LUC expression were isolated by luminescence imaging. Here we report on the ice1 mutant, which is impaired in the cold-induction of CBF3-LUC and is defective in cold acclimation. ICE1 encodes a MYC-like bHLH transcriptional activator that binds to the CBF3 promoter. Thus, ICE1 plays a key role in regulating cold-responsive gene expression and cold tolerance in Arabidopsis.

\section{Results}

Identification of the ICE1 locus

As noted above, Arabidopsis plants containing the CBF3-LUC transgene emitted bioluminescence in re-
A
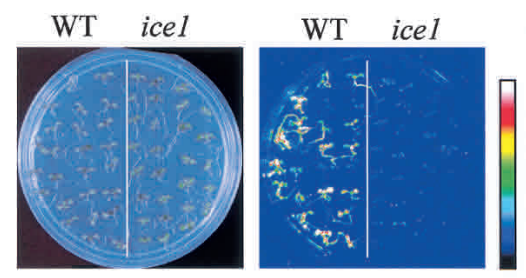

B

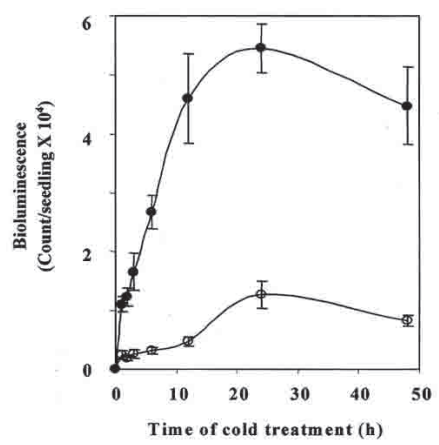

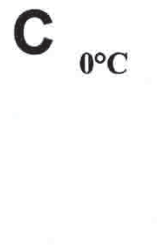

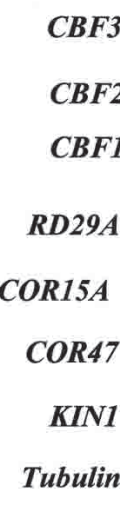

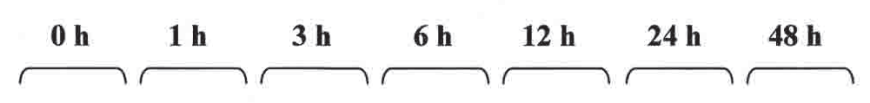
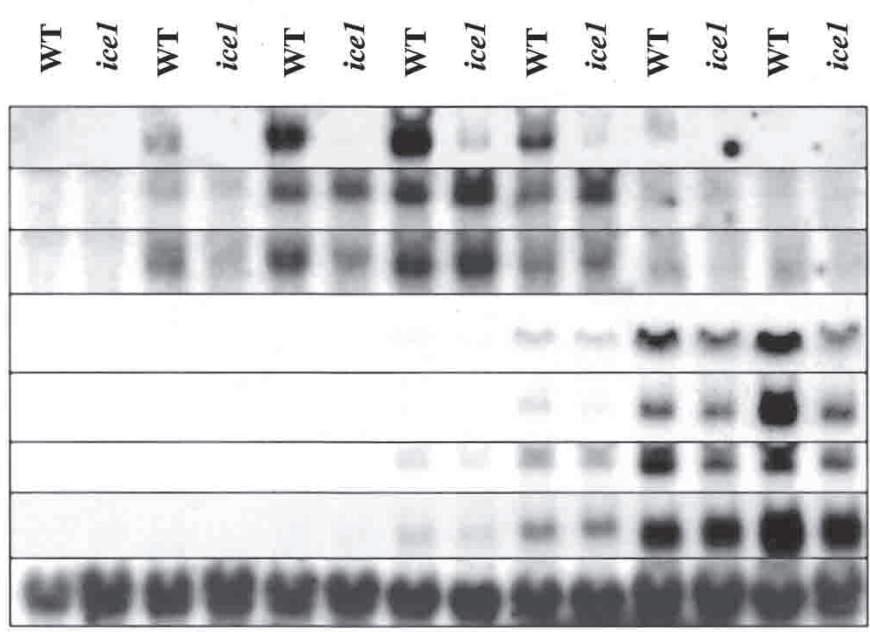

Figure 1. The ice1 mutation blocks the cold-induction of $C B F 3$ and affects the expression of other cold-responsive genes. $(A)$ Morphology (left) and CBF3-LUC luminescence images (right) of wild-type and ice1 seedlings. Luminescence images of the plants were collected after $12 \mathrm{~h}$ of cold $\left(0^{\circ} \mathrm{C}\right)$ treatment. $(B)$ Quantitation of the luminescence intensities of wild-type (solid circles) and ice 1 (open circles) seedlings in response to different durations of cold treatment. $(C)$ Transcript levels of $C B F s$ and their downstream target genes in wild-type and ice 1 plants in response to cold treatment. Seedlings were either not treated $(0 \mathrm{~h})$ or treated with cold $\left(0^{\circ} \mathrm{C}\right)$ for the indicated durations (h). The tubulin gene was used as a loading control. WT, wild type. 
sponse to cold stress (Fig. 1A,B). The homozygous CBF3-LUC plants (herein referred to as wild type) were mutagenized by ethylmethane sulfonate, and the resulting M2 population was screened for mutants with aberrant bioluminescence responses under cold stress using a low light imaging system (Chinnusamy et al. 2002). Several mutants showing abnormal cold regulation of CBF3-LUC expression were recovered. One of these mutant lines, designated as ice1, is virtually blocked in CBF3-LUC expression in the cold (Fig. 1A,B). In response to treatment at $0^{\circ} \mathrm{C}$, wild-type plants showed strong luminescence, while the ice1 mutant showed very little induction of luminescence throughout the duration of cold treatment (Fig. 1A,B). After $12 \mathrm{~h}$ of cold treatment, ice 1 plants showed nearly 10 times less luminescence than that of wild-type plants, and are obviously defective in the cold regulation of CBF3-LUC expression (Fig. 1B).

The ice1 mutant plant was crossed with CBF3-LUC wild-type plants and the resulting $\mathrm{F} 1$ plants were examined for CBF3-LUC expression after $12 \mathrm{~h}$ of cold treatment at $0^{\circ} \mathrm{C}$. As determined by luminescence imaging, all F1 plants showed reduced cold-induced CBF3-LUC expression similar to that of ice1. An F2 population from the selfed F1 segregated in an $\sim 3: 1$ ratio between mutant and wild type (data not shown). These results show that ice 1 is a dominant mutation in a single nuclear gene.

\section{ice1 mutant plants are defective in cold-regulated gene expression}

RNA blot analysis was carried out to analyze the effect of ice 1 mutation on the transcript levels of endogenous $C B F$ s and their target cold stress-responsive genes. Consistent with the imaging results, cold induction of the endogenous CBF3 gene was greatly impaired (almost abolished) in ice1 mutant plants (Fig. 1C). Wild-type plants showed $C B F 3$ induction after $1 \mathrm{~h}$ of cold stress and the expression peaked at $6 \mathrm{~h}$. In contrast, $C B F 3$ induction was almost abolished in ice1 plants (Fig. 1C). While the $C B F 1$ induction level in the ice 1 mutant was lower than that of wild type at 1 and $3 \mathrm{~h}$ of cold stress, its induction level at 6 and $12 \mathrm{~h}$ was similar to that in the wild type. The CBF2 induction level was slightly lower in ice 1 at 1 $\mathrm{h}$ of cold treatment, whereas at 6 and $12 \mathrm{~h}$, the induction level was higher in the mutant (Fig. 1C). We also examined the cold induction of the downstream target genes of CBFs. The expression levels of RD29A, COR15A, and $C O R 47 A$ under cold stress were lower in ice 1 than in the
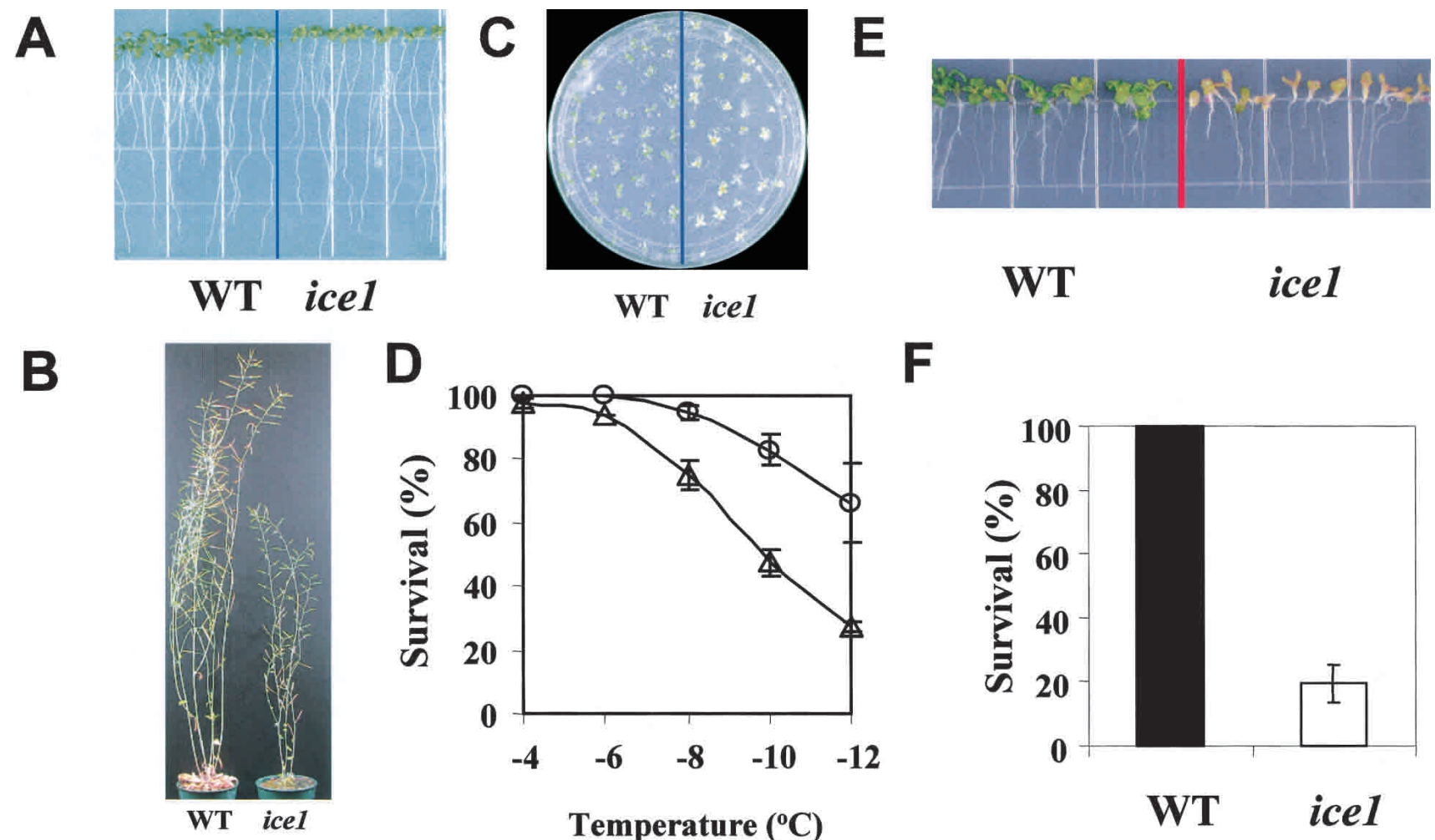

Figure 2. Morphology and freezing and chilling sensitivity of ice1 mutant plants. $(A)$ Wild-type and ice 1 seedlings in nutrient medium on agar under normal growth conditions. $(B)$ Wild-type and ice1 plants in soil under normal growth conditions. $(C)$ ice 1 plants are defective in cold acclimation. Ten-day-old seedlings grown at $22^{\circ} \mathrm{C}$ were incubated for $4 \mathrm{~d}$ in light at $4{ }^{\circ} \mathrm{C}$ before freezing treatment at $-12^{\circ} \mathrm{C}$. The picture was taken $3 \mathrm{~d}$ after the freezing treatment. $(D)$ Comparison of survival rates after freezing treatments at the indicated temperatures. Open circles and open triangles represent wild-type and ice 1 plants, respectively. $(E)$ ice 1 plants are sensitive to prolonged chilling treatment. After germination at $22^{\circ} \mathrm{C}$, the plants were grown at $4^{\circ} \mathrm{C}$ for 6 wk. $(F)$ Comparison of survival rates after 6 wk of chilling stress. 
wild type, while the induction of KIN1 was lower in ice 1 only after $48 \mathrm{~h}$ of cold stress (Fig. 1C).

Consistent with these RNA blot results, microarray analysis using Affymetrix near full genome genechips showed that out of 306 genes induced threefold or more in the wild type by a 6-h cold treatment, 217 are either not induced in the ice 1 mutant or their induction is $50 \%$ or less of that in the wild type (Supplementary Tables 1A, 2). Thirty-two of these encode putative transcription factors, suggesting that ICE1 may control many coldresponsive regulons. For 87 of the 306 cold-induced genes, their induction levels in the wild type and ice 1 differ by less than twofold (Supplementary Table 1B). Interestingly, two genes show higher levels of cold induction in the ice1 mutant (Supplementary Table 1C).

The icel mutation impairs chilling and freezing tolerance

At normal growth temperatures, ice 1 and wild-type seedlings were similar in size (Fig. 2A). Although adult ice1 plants were smaller, they were not very different from the wild type in flowering time and fertility (Fig. 2B). Ten-day-old seedlings of ice 1 and wild type grown on separate halves of the same agar plates were cold acclimated at $4^{\circ} \mathrm{C}$ for $4 \mathrm{~d}$ and then subjected to a freezing tolerance assay. The ice1 mutant was less freezing-tolerant than the wild type at all freezing temperatures (Fig. $2 \mathrm{C}, \mathrm{D})$. Freezing at $-10^{\circ} \mathrm{C}$ for $2 \mathrm{~h}$ killed about $50 \%$ of ice 1 mutant plants, whereas $<20 \%$ of wild-type plants were killed at this temperature (Fig. 2D). When newly germinated (at $22^{\circ} \mathrm{C}$ ) ice 1 and wild-type seedlings were transferred to $4^{\circ} \mathrm{C}$ (with $30 \pm 2 \mu$ mole quanta. $\mathrm{m}^{-2} \cdot \mathrm{s}^{-1}$ light), chilling injury became apparent in the mutant after $4 \mathrm{wk}$ of cold treatment (Fig. 2E). After 6 wk of chilling stress, $100 \%$ of wild-type but only $20 \%$ of ice 1 mutant plants survived (Fig. 2F).

\section{Positional cloning of ICE1}

To map the ice 1 mutation, a homozygous ice 1 mutant in the CBF3-LUC Columbia background was crossed to wild- type plants of the Ler ecotype. F1 plants from the cross were selfed to produce F2 seeds. Since the ice 1 mutation is dominant, we selected from the segregating F2 population seedlings with the wild-type phenotype (based on plant size and morphology) for mapping. A total of 662 wild-type plants were selected and used for mapping with simple sequence length polymorphism and cleaved amplified polymorphic sequence markers (see Materials and Methods section for details), which initially placed ICE1 on the middle of chromosome 3, then narrowed its location to a 58-kb region on the MLJ15 and MDJ14 BAC clones. Candidate genes in this region were amplified from homozygous ice1 mutant plants and sequenced. The sequences were compared with the published sequence of Arabidopsis ecotype Columbia and a single G-to-A mutation in the hypothetical MLJ15.14 gene was found.

To confirm that MLJ15.14 is the ICE1 gene, the MLJ15.14 gene including 2583 bp upstream of the initiation codon and $615 \mathrm{bp}$ downstream of the stop codon was cloned from ice1 mutant plants. This fragment was inserted into a binary vector and introduced into CBF3LUC Columbia wild-type plants by Agrobacterium-mediated transformation. Transgenic plants were selected based on their hygromycin resistance, and cold-induced bioluminescence in the $\mathrm{T} 2$ lines was compared with that of the wild type. The MLJ15.14 gene from ice1 suppressed cold-induced luminescence from the wild-type plants (Fig. 3A,B) and reduced the plant height to that of ice1 mutant (data not shown), thus confirming that MLJ15.14 is ICE1.

ICE1 encodes a constitutively expressed and nuclear-localized MYC-like bHLH transcription factor

The open reading frame of ICE1 was determined by sequencing cDNAs obtained by reverse transcriptase PCR (RT-PCR). ICE1 is predicted to encode a protein of 494 amino acids, with an estimated molecular mass of 53.5 $\mathrm{kD}$. Database searches revealed that ICE1 contains a MYC-like bHLH domain at its C-terminal half (Fig. $4 A, B)$. Over the entire length of the protein, ICE1 shows
Figure 3. Confirmation of ICE1 gene cloning by expressing the dominant ice 1 mutant allele in wild-type plants. (A) Expression in wild type of a genomic fragment containing the ice1 mutation recapitulates the ice1 mutant phenotype. Seven-day-old seedlings of the wild type, ice1, and wild type transformed with the mutant ice1 gene grown on MS agar medium were subjected to luminescence imaging after $12 \mathrm{~h}$ of cold $\left(0^{\circ} \mathrm{C}\right)$ stress. $(B)$ Quantitation of CBF3-LUC bioluminescence levels in wild type (WT), ice 1 and wild type transformed with the mutant ice 1 gene after $12 \mathrm{~h}$ of cold $\left(0^{\circ} \mathrm{C}\right)$ stress.
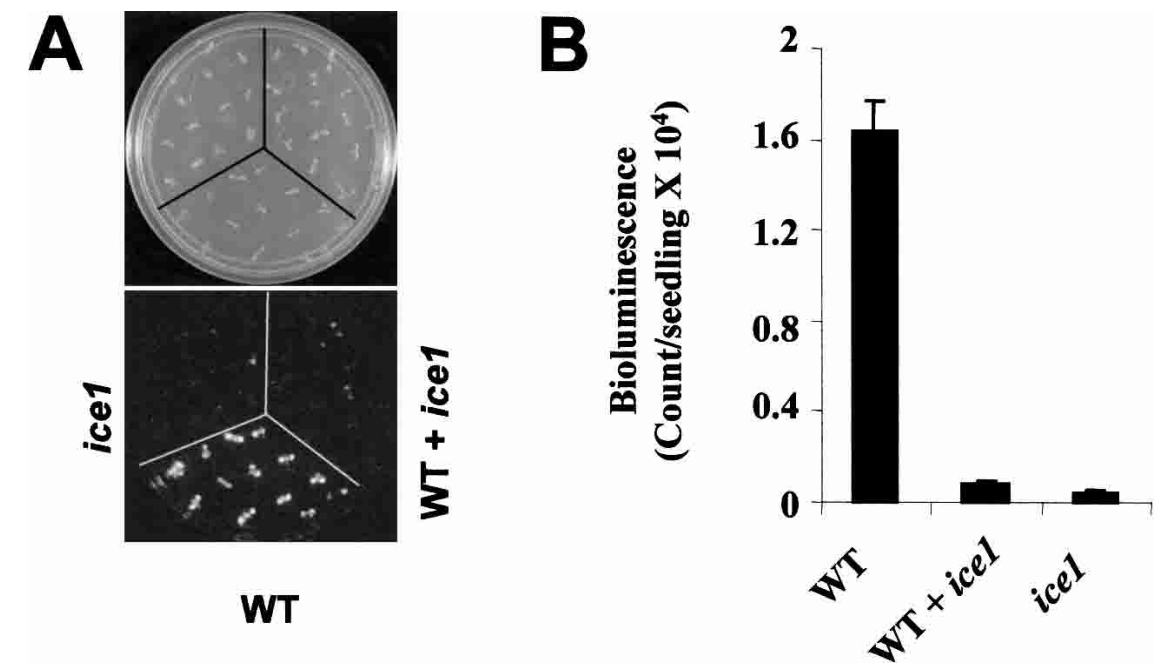


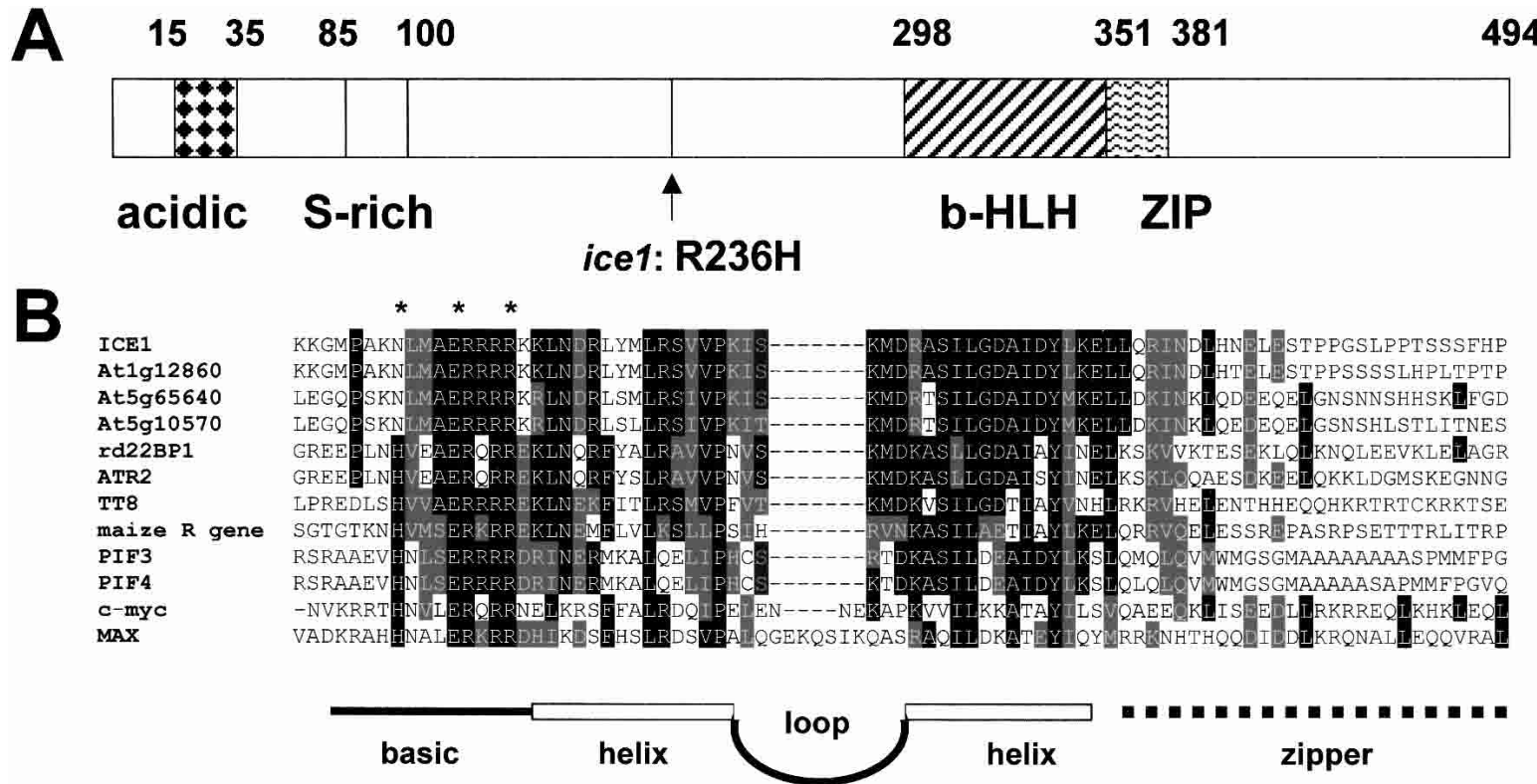

Figure 4. ICE1 encodes a bHLH protein. (A) Overall domain structure of ICE1 protein. A putative acidic domain (acidic), serine-rich region (S-rich), bHLH domain, and possible zipper region (ZIP) are indicated. The arrow indicates the amino acid residue changed in the ice1 mutant. (B) Sequence alignment of the bHLH domains and ZIP regions of ICE1 and other plant and animal bHLH proteins. Identical and similar residues are shown in black and gray, respectively. The basic region is indicated by a bold line and the helix-loop-helix domain is indicated by open boxes connected with a loop. The zipper region is indicated as a broken line. DDJB/ EMBL/GenBank accession numbers, with amino acid numbers in parentheses, are: ICE1, AY195621 (300-398); At1g12860, NM_101157 (638-731); At5g65640, NM_125962.1 (171-269); At5g10570, NM_121095.2 (144-242); rd22BP, AB000875 (446-544); ATR2, NM_124046.1 (409-507); maize R gene, M26227 (410-508); TT8, AJ277509 (357-455); PIF3, AF100166 (254-352); PIF4, AJ440755 (255-353); MAX, P52161 (21-107); c-myc, 1001205A (354-435). Asterisks indicate amino acid residues of MAX that are known to interact with nucleotides (Grandori et al. 2000).

amino acid sequence similarity to an unknown protein of Arabidopsis (At1g12860). The ice1 mutation changes Arg 236, conserved in these two Arabidopsis proteins, to His. The bHLH domain of ICE1 shows high amino acid similarity to that of known MYC-related bHLH transcription factors (Fig. 4B). All MYC binding promoter elements contain the CA nucleotides that are contacted by a conserved glutamic acid in the bHLH zipper domain (Grandori et al. 2000). This glutamic acid residue (Glu 312 ) is also conserved in the basic DNA binding domain of ICE1 (Fig. 4B). The bHLH family of transcription factors is characterized by an acidic domain near the $\mathrm{N}$ terminus and a conserved bHLH DNA binding and dimerization domain near the $\mathrm{C}$ terminus (Purugganan and Wessler 1994). All these features are present in ICE1 protein (Fig. 4A).

To analyze the expression pattern of ICE1 in different tissues, T2 lines of transgenic Arabidopsis plants expressing an ICE1 promoter-GUS transgene were analyzed. GUS expression was detected in roots, leaves, stem, and floral parts. Semiquantitative RT-PCR analysis also showed that ICE1 was expressed constitutively and the expression was stronger in leaves and stems than in other tissues (Fig. 5A,B). RNA blot analysis showed that the ICE1 transcript was slightly up-regulated by cold, $\mathrm{NaCl}$, and $\mathrm{ABA}$, but not by dehydration (Fig. 5C).

To examine the subcellular localization of the ICE1 protein, ICE1 was fused in-frame to the C-terminal side of the green fluorescent protein (GFP) and expressed under control of the CaMV 35S promoter. Confocal imaging of GFP fluorescence in T2 transgenic plants showed that the GFP-ICE1 fusion protein is present in the nucleus under either warm (Fig. 5D) or cold temperatures (data not shown).

\section{ICE1 binds to MYC recognition sites in the CBF3 promoter}

ICE1 has a bHLH domain and its amino acid sequence in the basic region is highly conserved with other bHLH proteins (Fig. 4B), and therefore may recognize promoter elements similar to the DNA binding sites for known bHLH proteins. These proteins recognize DNA with the consensus sequence CANNTG (Meshi and Iwabuchi 1995). In the promoter region of $C B F 3$, there are five potential MYC-recognition elements within a $1-\mathrm{kb}$ region upstream of the transcription initiation site (Shinwari et al. 1998). These possible MYC-recognition sites, designated MYC-1 through MYC-5, fall into four groups because MYC-3 and MYC-5 share the same consensus sequence, CATTTG (Fig. 6A). Thus, MYC-3 was used to represent both MYC-3 and MYC-5. To determine whether ICE1 binds to these MYC-recognition sites in 
Chinnusamy et al.
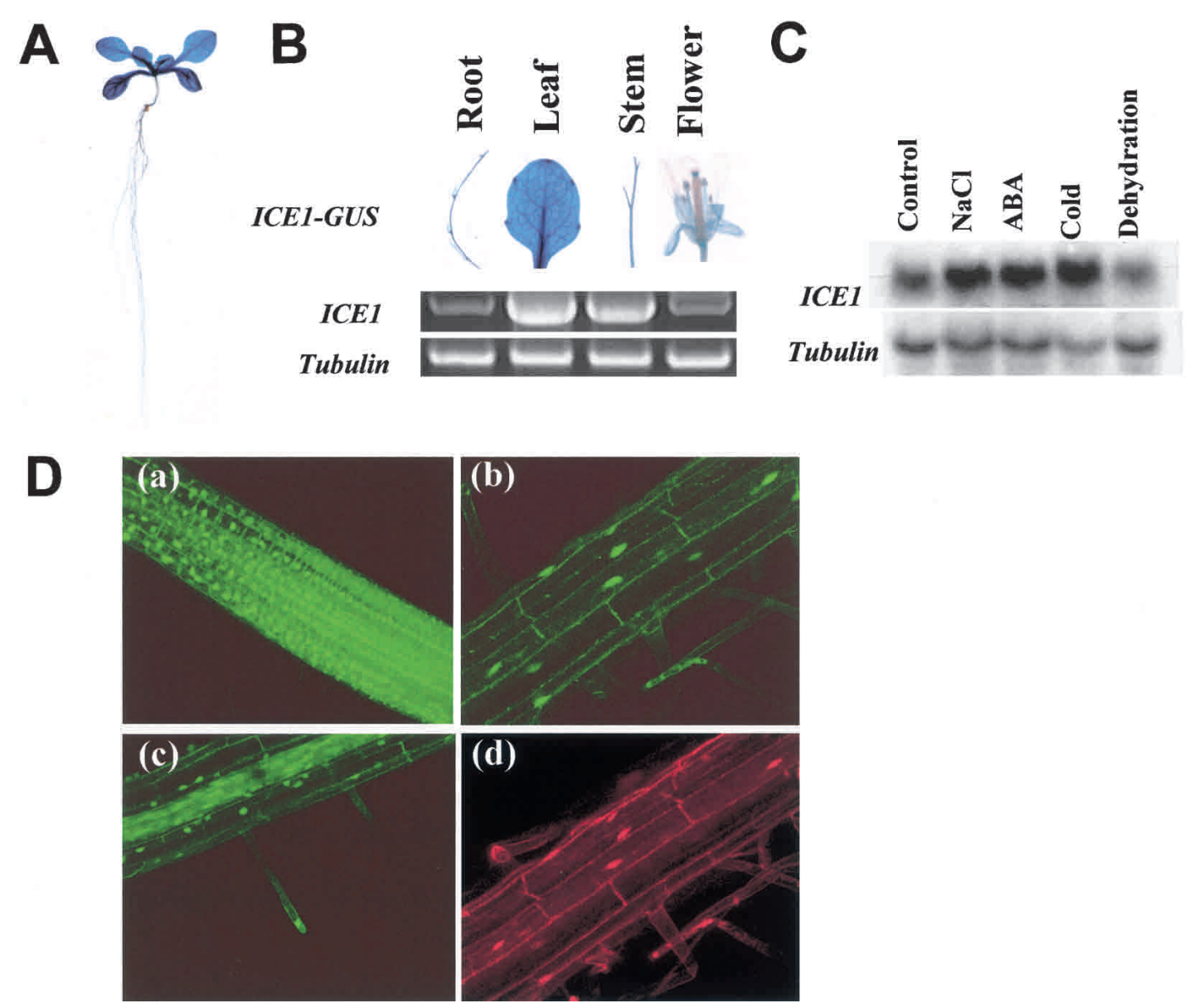

Figure 5. Expression of the ICE1 gene and subcellular localization of the ICE1 protein. $(A)$ ICE1 promoter-driven GUS expression pattern in a wild-type seedling. (B) ICE1 promoter-GUS expression in different plant tissues, and the corresponding ICE1 transcript levels as determined by RT-PCR analysis. The tubulin gene was used as an internal control in the RT-PCR. (C) RNA blot analysis of ICE1 expression in wild-type seedlings under various abiotic stresses. Plants with the following treatments are shown: control, MS salt only; NaCl, $300 \mathrm{mM} \mathrm{NaCl}$ for $5 \mathrm{~h}$; ABA, $100 \mu \mathrm{M}$ abscisic acid for $3 \mathrm{~h}$; Cold, $0^{\circ} \mathrm{C}$ for $2 \mathrm{~h}$; Dehydration, air drying for $30 \mathrm{~min}$. $(D)$ Localization of GFP-ICE1 fusion protein in the nucleus. Panels $a-c$ show confocal images of root cells in GFP-ICE1 transgenic plants, and panel $d$ shows the location of nuclei as indicated by propidium stain.

the $C B F 3$ promoter, we expressed and purified His-ICE1 fusion protein from E. coli. Four DNA fragments encompassing each possible MYC-recognition site were used for interaction with His-ICE1 in an electrophoresis mobility shift assay (EMSA).

Several complexes were observed when ICE1 was incubated with any of the four DNA fragments (MYC-1 through MYC-4), indicating that ICE1 is able to bind to these sequences (Fig. 6B). The MYC-2 fragment formed one major complex with ICE1, while the other DNA fragments formed several complexes with ICE1. These complexes were abolished by the addition of increasing amounts of cold competitors with the same sequences, but not by $\mathrm{P} 1$ or P2, which contains a putative MYBrecognition site and a nonrelated sequence, respectively (Fig. 6B). This specificity of competition strengthens the hypothesis that the interaction between DNA and ICE1 requires the MYC-recognition sequences. When the MYC-2 fragment was used as a probe, the complex was most efficiently competed off by the cold MYC-2 competitor, suggesting that ICE1 has a higher affinity for the MYC-2 site than for the other sites (Fig. 6C). The complex formed by ICE1 and the MYC-2 fragment was less affected by a mutated competitor than by the wild-type competitor (Fig. 6D). Together, these results show that ICE1 interacts specifically with the MYC-recognition sites in the $C B F 3$ promoter. The ice 1 mutation does not appear to affect ICE1 interaction with the CBF3 promoter, because the Arg 236 to His mutant form of ICE1 was also able to bind to the MYC-2 probe (Fig. 6E).

\section{ICE1 is a transcriptional activator that positively regulates $C B F$ expression}

Transient expression assays were carried out to determine whether ICE1 acts as a transcriptional activator or repressor. An effector plasmid was constructed by fusing ICE1 with the DNA binding domain of the yeast GAL4 


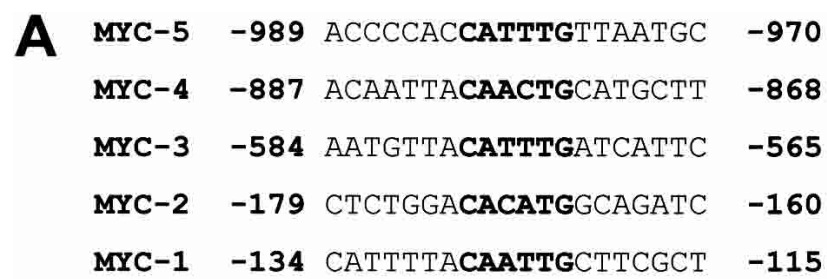

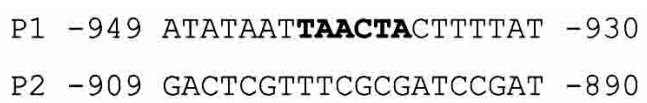

MYC-2 (wt) CTCTGGACACATGGCAGATC (M) CTCTGGAACCAGTGCAGATC

B
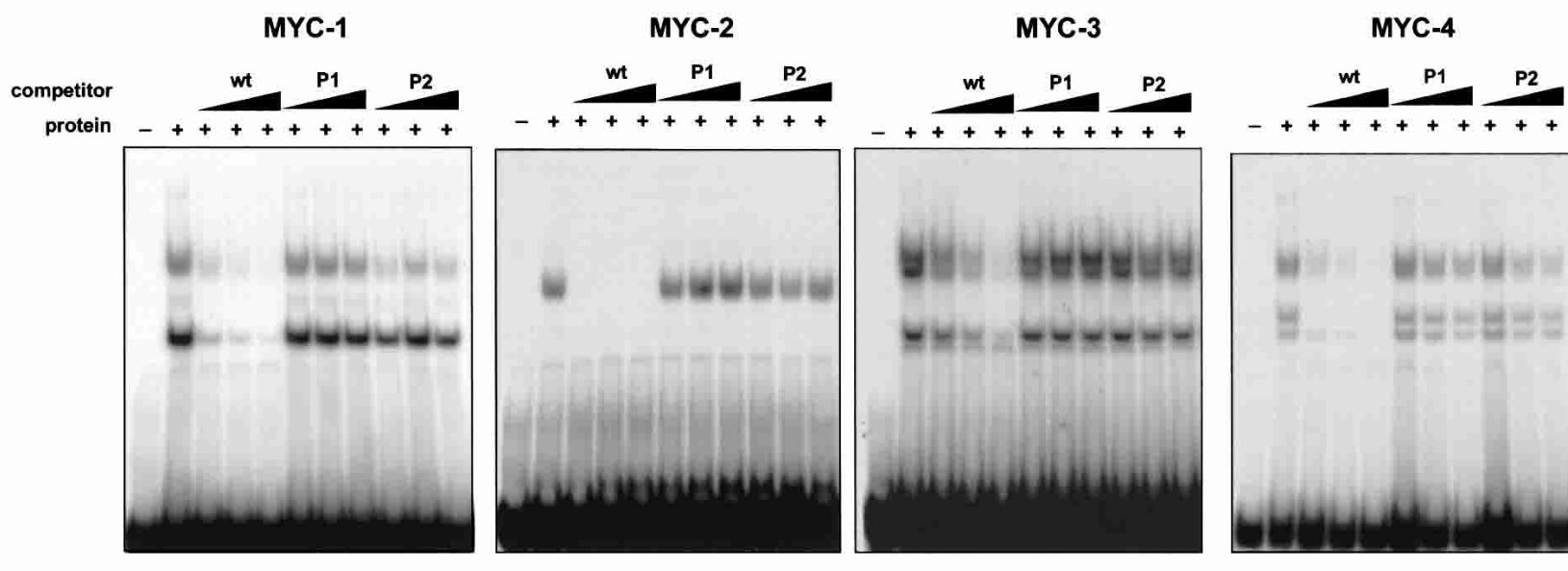

C
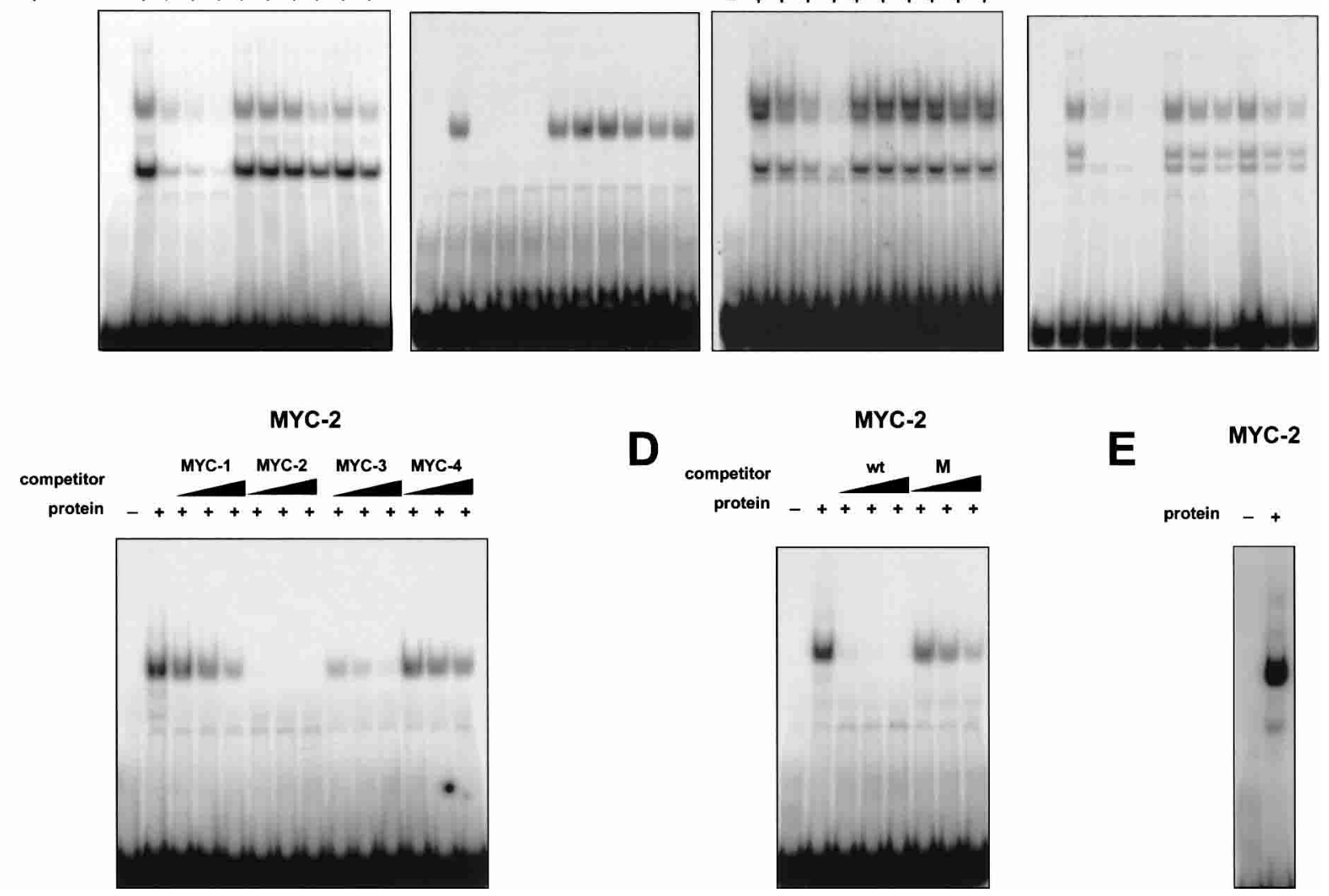

Figure 6. ICE1 protein binds to the MYC-recognition elements in the CBF3 promoter. (A) Sequences and positions of oligonucleotides within the CBF3 promoter used in the EMSA. Letters in bold indicate sequences of MYC-recognition motifs in MYC-1 through MYC-5. Bold letters in the P1 oligonucleotide are a putative MYB-recognition motif. (B) Interaction between ICE1 protein and ${ }^{32}$ P-labeled MYC-1 through MYC-4 DNA fragments. $(C)$ ICE1 binds to the MYC-2 DNA fragment more strongly than to the other DNA fragments. $(D)$ Consensus nucleotide residues in the MYC-recognition motif are important for the interaction between ICE1 and the MYC-2 DNA fragment. (E) ice1 mutant protein also binds to the MYC-2 DNA fragment. The labeled oligonucleotides used in each experiment are indicated at the top of each panel. Triangles indicate increasing amounts of unlabeled oligonucleotides for competition in $B, C$ and $D$, which correspond to 50-, 100-, and 250-fold excess of each probe.

transcriptional activator (GAL4-ICE1; Fig. 7A). When the wild-type GAL4-ICE1 and a GAL4-responsive reporter gene, GAL4-LUC, were delivered into Arabidopsis leaves by particle bombardment, the luciferase activity increased 20 -fold relative to the control with or without an effector plasmid containing only the GAL4 DNA binding domain (Fig. 7B). The Arg 236 to His mutant form of GAL4-ICE1 also activated the GAL4-responsive transcription (Fig. 7B). These results suggest that ICE1 is a transcriptional activator, and that the ice 1 mutation does not affect the function of the transcriptional activation domain.

A null allele of ice 1 created by T-DNA insertion does not show any phenotypes of the dominant ice 1 mutant (data not shown), suggesting that there is functional redundancy in the ICE1 gene family. We overexpressed ICE1 in wild-type Arabidopsis plants by using the strong constitutive super promoter. None of the overexpression 

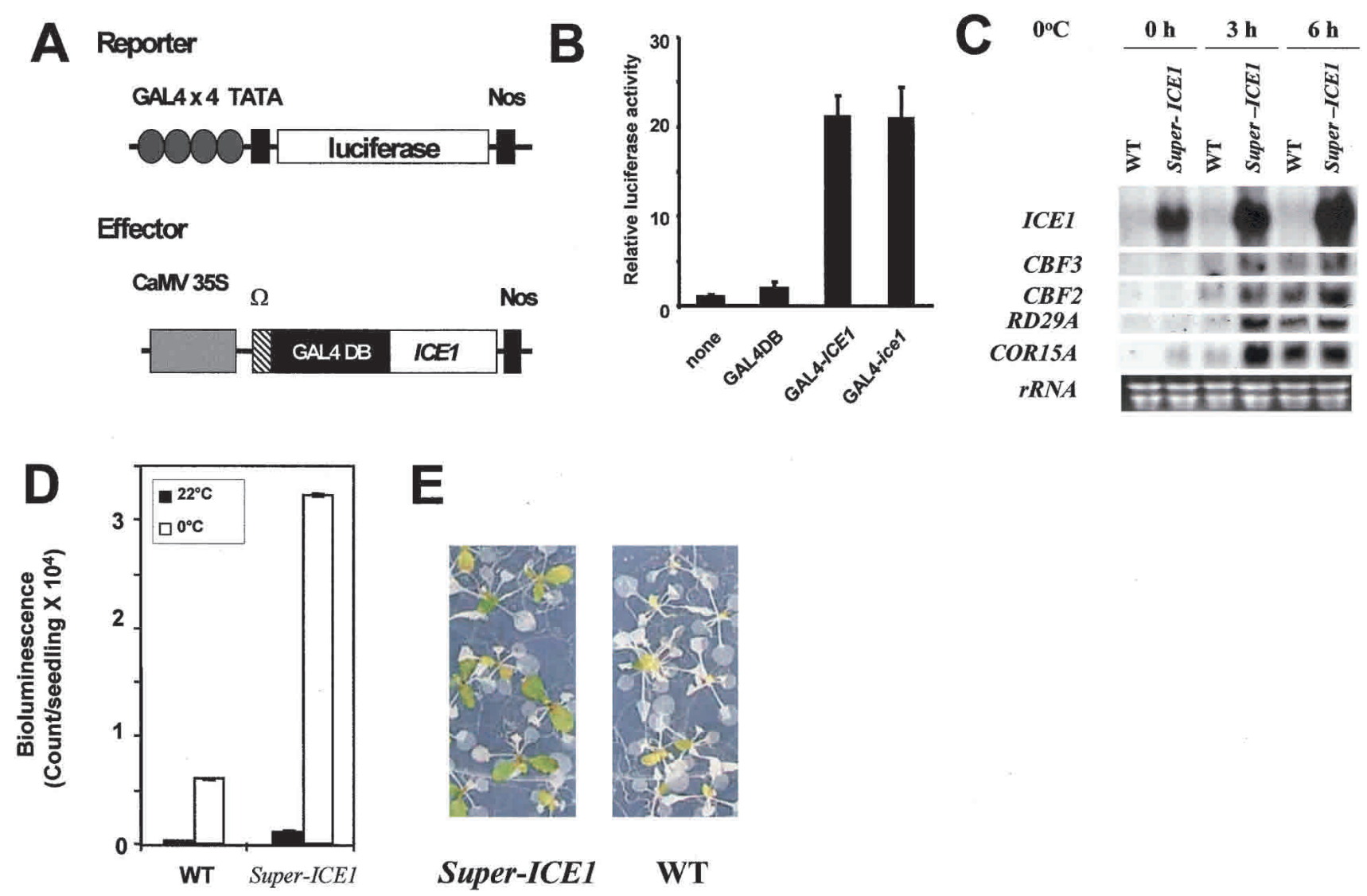

Figure 7. ICE 1 is a transcriptional activator and its overexpression enhances the $C B F$ regulon in the cold and improves freezing tolerance. (A) Schematic representation of the reporter and effector plasmids used in the transient expression assay. A GAL4-responsive reporter gene was used in this experiment. Nos, the terminator signal of the nopaline synthase gene; $\Omega$, the translational enhancer of tobacco mosaic virus; GAL4 DB, the DNA-binding domain of the yeast transcription factor GAL4. (B) Relative luciferase activities after transfection with GAL4-LUC and 35S-GAL4-ICE1 or 35S-GAL4-ice1. To normalize values obtained after each transfection, a gene for luciferase from Renilla was used as an internal control. Luciferase activity is expressed in arbitrary units relative to the activity of Renilla luciferase [as described in Ohta et al. (2001)]. The values are averages of three bombardments, and error bars indicate standard deviations. $(C)$ RNA blot analysis of ICE1 and cold-responsive gene expression in wild-type and ICE1 overexpressing transgenic (Super-ICE1) plants. Seedlings were either not treated $(0 \mathrm{~h})$ or treated with low temperature $\left(0^{\circ} \mathrm{C}\right)$ for 3 or $6 \mathrm{~h}$. Ethidium bromide stained rRNA bands are shown as loading control. (D) CBF3-LUC expression (indicated as luminescence intensity) in wild-type and ICE1 overexpressing transgenic (Super-ICE1) plants. (E) Improved survival of ICE1 overexpressing transgenic (Super-ICE1) plants after a freezing treatment.

lines showed any ice1 mutant phenotypes. RNA blot analysis showed that ICE1-overexpression did not activate $C B F 3$ expression at warm temperatures. However, ICE1-overexpression enhanced the expression of the endogenous $C B F 3$ gene as well as the $C B F 3-L U C$ reporter gene in the cold (Fig. 7C,D). Cold-induction of CBF2, $R D 29 A$, and COR15A was also enhanced in the SuperICE1 transgenic plants (Fig. 7C). When the Super-ICE1 transgenic plants and wild-type control plants in the same agar plates were cold acclimated at $4^{\circ} \mathrm{C}$ for $5 \mathrm{~d}$ and then subjected to freezing treatment at $-8^{\circ} \mathrm{C}$ for $4 \mathrm{~h}$, the ICE1 overexpression transgenic seedlings showed a higher survival rate $(75.9 \% \pm 6.5 \%)$ than that of control plants $(37.2 \% \pm 12.6 \%$; Fig. 7E). The ICE1 overexpression transgenic plants did not exhibit obvious growth or developmental abnormalities (data not shown). These results suggest that ICE1 is a positive regulator of $C B F 3$, and that the dominant nature of ice 1 is likely caused by a dominant negative effect of the mutation.

\section{Discussion}

Cold temperatures trigger the transcription of the CBF family of transcription factors, which in turn activate the transcription of genes containing the DRE/CRT promoter element (Thomashow 1999). The CBF target genes presumably include some transcription factors (Fowler and Thomashow 2002). Therefore, cold signaling for freezing tolerance requires a cascade of transcriptional regulations. In the present study, we have identified ICE1, a very upstream transcription factor of this cascade. Our results show that ICE1 is a positive regulator of $C B F 3$ and has a critical role in cold acclimation. ICE1 encodes a MYC-like bHLH transcription factor. Five pu- 
tative MYC recognition sequences are present in the $C B F 3$ promoter, while $C B F 1$ and $C B F 2$ promoters each contain one such element (Shinwari et al. 1998). This is consistent with the fact that $C B F 3$ is more strongly affected by the ice1 mutation than are CBF1 or CBF2. DNA binding assays showed that ICE1 can specifically bind to the MYC recognition sequences on the CBF3 promoter but not to a putative MYB recognition sequence (Fig. 6). The ice1 mutation abolishes CBF3 expression, and reduces the expression of CBF-target genes in the cold. Consistent with its role in cold-responsive gene regulation, ICE1 is important for chilling and freezing tolerance of Arabidopsis plants.

The ice1 mutation also affects the cold-induction of $C B F 1$ and $C B F 2$; their expression is slightly reduced early in the cold, but at later time points the expression is not reduced. Instead, the expression of CBF2 is actually enhanced in the ice 1 mutant after 6 and $12 \mathrm{~h}$ of cold treatment. The expression of $C B F$ genes is known to be repressed by their gene products or the products of their downstream target genes (Guo et al. 2002). The correlation between the reduced $C B F 3$ expression and enhanced $C B F 2$ induction suggests that $\mathrm{CBF} 3$ may repress $C B F 2$ expression. When the $C B F 2$ gene is disrupted, $C B F 1$ and $C B F 3$ show more sustained induction in the cold (J. Salinas, pers. comm.), suggesting that $\mathrm{CBF} 2$ may repress the expression of $C B F 1$ and $C B F 3$. The potential negative regulation of each other among the $\mathrm{CBF}$ transcription factor genes may be important for ensuring that their expression is transient and tightly controlled.

The three $C B F$ genes are generally presumed to be functionally redundant. Their individual contribution has not been examined by loss-of-function analysis. Even though the ice 1 mutation only blocks the expression of $C B F 3$, the downstream genes such as $R D 29 A, C O R 15 A$, and $C O R 47$ are substantially affected. This suggests that $\mathrm{CBF} 3$ plays a critical role in the cold regulation of these genes. In comparison, the cold regulation of KIN1 is less affected by the ice 1 mutation. Therefore, it is possible that the three $C B F$ genes may each have their own set of preferred target genes.

ICE1 is expressed constitutively in all tissues (Fig. $5 \mathrm{~A}, \mathrm{~B}$ ), and is only slightly up-regulated by cold (Fig. 5C). Consistent with what has been speculated for "ICE" proteins (Gilmour et al. 1998), cold-induced modification of the ICE1 protein or of a transcriptional cofactor appears to be necessary for ICE1 to activate the expression of CBFs. This is supported by our evidence because ICE1 is expressed constitutively and localized in the nucleus, but the $C B F$ expression requires cold treatment; and transgenic lines constitutively overexpressing ICE1 do not show $C B F 3$ expression at warm temperatures, but have a higher level of $C B F 3$ expression at cold temperatures. The ability of transcription factors to activate gene transcription may be regulated by protein phosphorylation and dephosphorylation in the cytoplasm or in the nucleus (reviewed by Liu et al. 1999). The ice1 mutation is very near potential serine phosphorylation residues (Ser 243 and Ser 245), and thus might affect the phosphorylation/dephosphorylation of ICE1.
It is known that MYC-related bHLH transcription factors require MYB cotranscription factors and/or WD-repeat containing factors for transcriptional activation of target genes (Spelt et al. 2000; Walker et al. 1999). The promoters of $C B F$ s contain MYC as well as potential MYB recognition sequences (Shinwari et al. 1998), suggesting that a MYB-related transcription factor may also be involved in the cold induction of CBFs. The ice $1 \mathrm{mu}-$ tation, which substitutes Arg 236 with His, may interfere with hetero-oligomer formation between ICE1 and an ICE1-like protein or a MYB-related cofactor. Alternatively, the putative dominant negative effect of ice1 could be a consequence of icel interference with potential ICE1 homo-oligomer formation, protein stability, nuclear localization, or cold-induced posttranslational modification of ICE1.

\section{Materials and methods}

\section{Plant materials and mutant isolation}

The CBF3 promoter, a region from 1126 to $100 \mathrm{bp}$ upstream of the initiation codon, was obtained by PCR using the following primer pair: 5'-TCATGGATCCACCATTTGTTAATGCAT GATGG-3' and 5'-GCTCAAGCTTTCTGTTCTAGTTCAGG $3^{\prime}$. This promoter was placed in front of the firefly luciferase $(L U C)$ coding sequence in a plant transformation vector (Ishitani et al. 1997). Arabidopsis thaliana ecotype Columbia (with the glabrous1 mutation) was transformed with Agrobacterium tumefaciens containing this CBF3-LUC construct by the floral dipping method. Plants homozygous for the CBF3-LUC transgene were selected from the second generation after transformation. One such plant with a single copy of the CBF3-LUC transgene was chosen for subsequent experiments (hereafter referred to as wild type). This wild-type plant did not show any bioluminescence when grown under normal growth conditions, but emitted bioluminescence when cold stress was imposed. The CBF3-LUC plant seeds were mutagenized with ethyl methanesulfonate (EMS). Seedlings of the M2 generation were used to screen for mutants defective in cold-regulated CBF3-LUC expression by luminescence imaging. Seven-day-old seedlings grown on $0.6 \%$ agar plates containing $3 \%$ sucrose and $1 \times \mathrm{Mu}-$ rashige and Skoog (MS) salts (JRH Biosciences) were screened for deregulated luciferase expression in response to low temperature treatment at $0^{\circ} \mathrm{C}$ for $12 \mathrm{~h}$, using a low-light video imaging system (Princeton Instruments). Luminescence intensities of individual seedlings were quantified with the WinView software provided by the camera manufacturer (Princeton Instruments; Chinnusamy et al. 2002).

\section{Chilling and freezing tolerance assays}

Chilling sensitivity of ice 1 and wild-type plants were tested by exposing the seedlings immediately after radicle emergence. After $2 \mathrm{~d}$ of stratification at $4^{\circ} \mathrm{C}$, mutant and wild-type seeds were germinated at $22^{\circ} \mathrm{C}$ on MS nutrient medium with $3 \%$ sucrose and $1.2 \%$ agar. Chilling stress was imposed by incubating the seedlings at $4^{\circ} \mathrm{C} \pm 1^{\circ} \mathrm{C}$ with $30 \pm 2 \mu$ mole quanta. $\mathrm{m}^{-2} \cdot \mathrm{s}^{-1}$ light. Freezing tolerance was assayed as described (Xin and Browse 1998). Briefly, wild-type and ice1 seeds were sown on agar $(0.9 \%)$ plates with Gamborg basal salts and $1.5 \%$ sucrose. After $2 \mathrm{~d}$ of stratification at $4^{\circ} \mathrm{C}$, the plates were kept at $22^{\circ} \mathrm{C}$ under 50 $\pm 2 \mu$ mole quanta $\mathrm{m}^{-2} \cdot \mathrm{s}^{-1}$ continuous light. Ten-day-old seed- 
lings were cold acclimated at $4^{\circ} \mathrm{C} \pm 1^{\circ} \mathrm{C}$ and $30 \pm 2 \mu$ mole quanta. $\mathrm{m}^{-2} \cdot \mathrm{s}^{-1}$ light for $4 \mathrm{~d}$. These plants on petri dishes were placed on ice in a freezing chamber (Percival Scientific) set to $-1^{\circ} \mathrm{C} \pm 0.1^{\circ} \mathrm{C}$ for $16 \mathrm{~h}$. Ice chips were sprinkled on these plants before the chamber was programmed to cool at $1^{\circ} \mathrm{C} \mathrm{h}^{-1}$. Petri dishes of plants were removed after being frozen at desired temperatures for $2 \mathrm{~h}$ unless indicated otherwise, thawed at $4^{\circ} \mathrm{C}$ for $12 \mathrm{~h}$ in the dark, and then transferred to $22^{\circ} \mathrm{C}$ under $50 \pm 2$ umole quanta. $\mathrm{m}^{-2} \cdot \mathrm{s}^{-1}$ continuous light. Survival of the seedlings was scored visually after $2 \mathrm{~d}$.

\section{Gene expression analysis}

For RNA analysis, 10-day-old seedlings of wild-type and ice1 plants grown on separate halves of the same MS agar plates were used. Total RNA extracted from control and stressed plants was analyzed by RNA blotting as described by Liu and Zhu (1997). The RD29A gene-specific probe was from the 3' noncoding region (Liu and Zhu 1997). COR15A and COR47 cDNAs (Gilmour et al. 1992; Lin and Thomashow 1992) were kindly provided by M.F. Thomashow (Michigan State University). The $C B F 2$ and $C B F 3$ gene-specific probes were generated by PCR with the following primer pairs: CBF2-forward primer, $5^{\prime}$-TTC GATTTTTATTTCCATTTTTGG-3'; CBF2-reverse primer, 5'CCAAACGTCCTTGAGTCTTGAT-3'; CBF3-forward primer, 5'-TAAAACTCAGATTATTATTTCCATTT-3'; CBF3-reverse primer, 5'-GAGGAGCCACGTAGAGGGCC-3'. The probe for KIN1 (Kurkela and Franck 1990) was a 0.4-kb EcoRI fragment of the Arabidopsis EST clone YAP368T7. The $\beta$-tubulin gene was used as a loading control and was amplified by PCR with the following primer pairs: forward primer (5'-CGTGGATCA CAGCAATACAGAGCC-3') and reverse primer (5'-CCTCCT GCACTTCCACTTCGTCTTC-3').

For Affymetrix GeneChip array analysis, $20 \mu \mathrm{g}$ of total RNA from the wild-type and ice1 seedlings with or without cold treatment (6 h under light) were extracted using the RNeasy Plant Mini Kit (Qiagen) and used to make biotin-labeled cRNA targets. The Affymetrix Arabidopsis ATH1 genome array GeneChips, which contain $>22,500$ probe sets representing $\sim 24,000$ genes, were used and hybridization, washing, and staining were carried out as directed in the manufacturer's manual. Microarray data were extracted from scanned GeneChip images and analyzed using Microarray Suite version 5.0.1 (Affymetrix).

\section{Mapping and cloning of the ICE1 locus}

Genetic analysis of $F_{1}$ and $F_{2}$ progenies of the ice 1 cross with wild type showed that ice 1 is a dominant mutation. Hence, to clone ICE1, a homozygous ice1 plant was crossed with the Arabidopsis Landsberg erecta (Ler) ecotype and the $\mathrm{F}_{2}$ progeny from self-pollinated $F_{1}$ were used to select mapping samples with the wild-type phenotype. Genomic DNA extracted from these seedlings was used for PCR-based mapping with simple sequence polymorphism markers or cleaved amplified polymorphic sequence markers. New SSLP mapping markers on F16J4, MTC11, MLJ15, MDJ14, K17E12, and T32N15 BAC clones were developed based on insertion/deletions identified from the Cereon Arabidopsis polymorphism and Ler sequence collection (http://www.arabidopsis.org). Genomic DNA corresponding to candidate genes was amplified by PCR from ice 1 mutant and wild-type plants and sequenced to identify the ice1 mutation.

For ice1 mutant complementation, the MLJ15.14 gene, including $2583 \mathrm{bp}$ upstream of the initiation codon and $615 \mathrm{bp}$ downstream of the stop codon, was PCR-amplified by LA Taq polymerase (Takara) using ice1 mutant genomic DNA as template. The PCR primers used were as follows: forward primer:
5'-AGGGATCCGGACCACCGTCAATAACATCGTTAAGT AG-3'; reverse primer: 5'-CGAATTCTAACCGCCATTAAC TATGTCTCCTCTCTATCTC-3'. The resulting 5035-bp fragment was T-A cloned into the pCR2.1 TOPO vector (Invitrogen) and then subcloned into pCAMBIA1200 between the BamHI and EcoRI sites. This and all other constructs described here were completely sequenced to ensure that they did not contain PCR or cloning errors. The binary construct was then introduced into Agrobacterium strain GV3101 and transformed into CBF3-LUC Columbia wild-type plants. Hygromycin-resistant transgenic plants were selected and their T2 progenies were tested for CBF3-LUC expression in response to cold stress.

\section{Analysis of ICE1 expression}

The promoter region (2589 bp upstream from the initiation codon) of the ICE1 gene was PCR-amplified with the following primer pair: forward primer, 5'-AGGGATCCGGACCACCGT CAATAACATCGTTAAGTAG-3'; reverse primer, 5'-CGAAT TCGCCAAAGTTGACACCTTTACCCCAAAG-3'. The resulting fragment was digested with $B a m H I$ and EcoRI and inserted into the pCAMBIA1391 binary vector. This ICE1 promoterGUS construct was introduced into Agrobacterium strain GV3101 and transformed into wild-type Arabidopsis. T2 transgenic lines resistant to hygromycin were analyzed for ICE1promoter driven GUS expression. For GUS staining, T2 seedlings grown on MS agar plates were incubated with X-Gluc. for $12 \mathrm{~h}$ at $37^{\circ} \mathrm{C}$ and then washed 5 times with $70 \%(\mathrm{v} / \mathrm{v})$ ethanol at $70^{\circ} \mathrm{C}$ to remove chlorophyll. ICE1 expression was also examined by quantitative RT-PCR analysis of RNA prepared from wild-type roots, leaves, stems, and flowers. The ICE1 cDNA was amplified by RT-PCR using the following primers: forward primer: 5'-GCGATGGGTCTTGACGGAAACAATGGTG-3' and reverse primer $5^{\prime}$-TCAGATCATACCAGCATACCCTGC TGTATCG-3'. The tubulin gene was used as an internal control in the RT-PCR analysis. Tubulin cDNA was amplified using the following primers: forward primer: 5'-GTCAAGAG GTTCTCAGCAGTA-3' and reverse primer 5'-TCACCTTCT TGATCCGCAGTT- $3^{\prime}$.

\section{Overexpression of ICE1}

The ICE1 cDNA was amplified from Arabidopsis (ecotype Columbia) RNA by RT-PCR using the following primers: a forward primer: 5'-GCTCTAGAGCGATGGGTCTTGACGGAA ACAATGGTG-3' and a reverse primer 5'-GGGGTACCTC AGATCATACCAGCATACCCTGCTGTATCG-3'. The PCR product was digested with $\mathrm{Xba \textrm {I }}$ and $\mathrm{KpnI}$, and cloned into the pBIB vector under control of the superpromoter, which consists of three copies of the octopine synthase upstream-activating sequence in front of the manopine synthase promoter (Li et al. 2001). Agrobacterium tumefaciens strain GV3101 containing this binary construct was used to transform Arabidopsis plants. Transformants were selected on MS medium containing hygromycin $(30 \mathrm{mg} / \mathrm{L})$.

\section{Expression and localization of GFP-ICE1 fusion protein}

The full-length ICE1 cDNA was obtained from wild-type plants by RT-PCR using the following primers: forward primer, 5'AGGAATTCGCGATGGGTCTTGACGGAAACAATGGTG3'; reverse primer, 5'-CTGGATCCTCAGATCATACCAG CATACCCTGCTGTATCG-3'. The resulting PCR fragment was digested with EcoRI and BamHI and cloned into the binary vector pEGAD downstream from the CaMV $35 \mathrm{~S}$ promoter. This 
GFP-ICE1 construct was introduced into Agrobacterium strain GV3101 and transformed into wild-type Arabidopsis. T2 transgenic lines resistant to Basta (glufosinate) were selected and analyzed for GFP expression. To visualize the nucleus, root tissues were stained with propidium iodide $(1 \mu \mathrm{g} / \mathrm{mL})$. Green fluorescence (GFP expression) and red fluorescence (propidium iodide staining) analyses of transgenic plants were performed with a confocal laser-scanning microscope.

\section{DNA binding assay}

The wild-type and mutant ICE1 cDNAs were amplified by RTPCR and inserted into NdeI and BamHI sites in the expression vector pET14b (Novagen). Wild-type and mutant His-ICE1 fusion proteins were prepared from E. coli cells (BL21 DE3) according to the instruction manual of His-Bind Buffer Kit (Novagen). The electrophoresis mobility shift assay (EMSA) was carried out as described (Hao et al. 1998). The following doublestranded oligonucleotides listed in Figure 6A (MYC-1, MYC-2, MYC-3, MYC-4, and MYC-5) were used as probes and competitors in EMSAs. Nucleotide sequences P1 (-949 to -930) and P2 (-909 to -890) were also used as competitors. P1 contains a putative MYB-recognition site. P2 does not contain any typical cis-elements. DNA probes were end-labeled with $\left[\gamma_{-}{ }^{32} \mathrm{P}\right] \mathrm{dCTP}$ using the Klenow fragment and purified through a Sephadex G-50 column. The labeled probes (ca 0.02 pmole) were incubated for $20 \mathrm{~min}$ at room temperature with $2.3 \mu \mathrm{g}$ of purified His-ICE1 fusion protein in $1 \times$ binding buffer (Hao et a.1998) supplemented with 20 pmole poly(dI-dC). The resulting DNAprotein complexes were resolved by electrophoresis on a $6 \%$ polyacrylamide gel in $0.5 \times$ TBE buffer and visualized by autoradiography. For competition experiments, unlabeled competitors were incubated with the His-ICE1 fusion protein on ice for $30 \mathrm{~min}$ prior to the addition of labeled probes.

\section{Transient expression assay}

The wild-type (ICE1) and mutant (ice1) cDNAs were amplified by RT-PCR, digested with SalI and inserted into SmaI and SalI sites of the plant expression vector 35S-GAL4 DB (Ohta et al. 2000). The plasmid DNA of the resulting effector, GAL4-ICE1, and a GAL4 responsive reporter, GAL4-LUC (Ohta et al. 2000) were delivered into Arabidopsis leaves using particle bombardment (Ohta et al. 2001).

\section{Acknowledgments}

We sincerely thank Dr. Andre Jagendorf for a critical review on the manuscript and Becky Stevenson for excellent technical assistance. This work was supported by National Science Foundation grant IBN-0212346 and USDA NRI grant 2000-00664. V. Chinnusamy was supported in part by the BOYSCAST fellowship from the DST, GOVT of India and by ICAR, New Delhi, India.

The publication costs of this article were defrayed in part by payment of page charges. This article must therefore be hereby marked "advertisement" in accordance with 18 USC section 1734 solely to indicate this fact.

\section{References}

Browse, J. and Xin, Z. 2001. Temperature sensing and cold acclimation. Curr. Opin. Plant Biol. 4: 241-246.

Chinnusamy, V., Stevenson, B., Lee, B., and Zhu, J. 2002. Screening for gene regulation mutants by bioluminescence imaging. Science's STKE http://stke.sciencemag.org/cgi/ content/full/sigtrans;2002/140/pl10.

Fowler, S. and Thomashow, M.F. 2002. Arabidopsis transcriptome profiling indicates that multiple regulatory pathways are activated during cold acclimation in addition to the CBF cold response pathway. Plant Cell 14: 1675-1690.

Gilmour, S.J., Artus, N.N., and Thomashow, M.F. 1992. cDNA sequence analysis and expression of two cold regulated genes of Arabidopsis thaliana. Plant Mol. Biol. 18: 13-32.

Gilmour, S.J., Zarka, D.G., Stockinger, E.J., Salazar, M.P., Houghton, J.M., and Thomashow, M.F. 1998. Low temperature regulation of the Arabidopsis CBF family of AP2 transcriptional activators as an early step in cold-induced $C O R$ gene expression. Plant J. 16: 433-442.

Gong, Z., Lee, H., Xiong, L., Jagendorf, A., Stevenson, B., and Zhu, J.-K. 2002. RNA helicase-like protein as an early regulator of transcription factors for plant chilling and freezing tolerance. Proc. Natl. Acad. Sci. 99: 11507-11512.

Grandori, C., Cowley, S.M., James, L.P., and Eisenman, R.N. 2000. The MYC/MAX/MAD network and the transcriptional control of cell behavior. Annu. Rev. Cell. Dev. Biol. 16: 653-699.

Guo, Y., Xiong, L., Ishitani, M., and Zhu, J.-K. 2002. An Arabidopsis mutation in translation elongation factor 2 causes superinduction of CBF/DREB1 transcription factor genes but blocks the induction of their downstream targets under low temperature. Proc. Nat1. Acad. Sci. 99: 7786-7791.

Guy, C.L. 1990. Cold acclimation and freezing stress tolerance: Role of protein metabolism. Annu. Rev. Plant Physiol. Plant Mol. Biol. 41: 187-223.

Hao, D., Ohme-Takagi, M., and Sarai, A. 1998. Unique mode of GCC box recognition by the DNA binding domain of ethylene-responsive element binding factor (ERF domain) in plant. J. Biol. Chem. 273: 26857-26861.

Hsieh, T.H., Lee, J.T., Yang, P.T., Chiu, L.H., Charng, Y.Y., Wang, Y.C., and Chan, M.T. 2002. Heterology expression of the Arabidopsis C-repeat/dehydration response element binding factor 1 gene confers elevated tolerance to chilling and oxidative stresses in transgenic tomato. Plant Physiol. 129: $1086-1094$.

Hughes, M. and Dunn, M. 1996. The molecular biology of plant acclimation to low temperature. J. Exp. Bot. 47: 291-305.

Ishitani, M., Xiong, L., Stevenson, B., and Zhu, J.K. 1997. Genetic analysis of osmotic and cold stress signal transduction in Arabidopsis: Interactions and convergence of abscisic acid-dependent and abscisic acid-independent pathways. Plant Cell 9: 1935-1949.

Ishitani, M., Xiong, L., Lee, H., Stevenson, B., and Zhu, J.K. 1998. HOS1, a genetic locus involved in cold-responsive gene expression in Arabidopsis. Plant Cell 10: 1151-1161.

Jaglo-Ottosen, K.R., Gilmour, S.J., Zarka, D.G., Schabenberger, O., and Thomashow, M.F. 1998. Arabidopsis CBF1 overexpression induces cor genes and enhances freezing tolerance. Science 280: 104-106.

Knight, H., Veale, E.L., Warren, G.J., and Knight, M.R. 1999. The sfr6 mutation in Arabidopsis suppresses low-temperature induction of genes dependent on the CRT/DRE sequence motif. Plant Cell 11: 875-886.

Kurkela, S. and Franck, M. 1990. Cloning and characterization of a cold- and ABA-inducible Arabidopsis gene. Plant Mol. Biol. 15: 137-144.

Lee, H., Xiong, L., Gong, Z., Ishitani, M., Stevenson, B., and Zhu, J.K. 2001. The Arabidopsis HOS1 gene negatively regulates cold signal transduction and encodes a RING finger protein that displays cold-regulated nucleo-cytoplasmic partitioning. Genes \& Dev. 15: 912-924. 
Lee, H., Guo, Y., Ohta, M., Xiong, L., Stevenson, B., and Zhu, J.-K. 2002. LOS2, a genetic locus required for cold-responsive gene transcription encodes a bifunctional enolase. EMBO $J$. 21: 2692-2702.

Li, X., Gong, Z., Koiwa, H., Niu, X., Espartero, J., Zhu, X., Veronese, P., Ruggiero, B., Bressan, R., Weller, S.C., et al. 2001. Bar-expressing peppermint (Mentha $\times$ Piperita L. var. Black Mitcham) plants are highly resistant to the glufosinate herbicide Liberty. Mol. Breed. 8: 109-118.

Lin, C. and Thomashow, M.F. 1992. DNA sequence analysis of a complementary DNA for cold-regulated Arabidopsis gene cor15 and characterization of the COR15 polypeptide. Plant Physiol. 99: 519-525.

Liu, J. and Zhu, J.-K. 1997. Proline accumulation and salt-stressinduced gene expression in a salt-hypersensitive mutant of Arabidopsis. Plant Physiol. 114: 591-596.

Liu, L., White, M.J., and MacRae, T.H. 1999. Transcription factors and their genes in their genes in higher plants: Functional domains, evolution and regulation. Eur. J. Biochem. 262: 247-257.

Liu, Q., Sakuma, Y., Abe, H., Kasuga, M., Miura, S., YamaguchiShinozaki, K., and Shinozaki, K. 1998. Two transcription factors, DREB1 and DREB2, with an EREBP/AP2 DNA binding domain, separate two cellular signal transduction pathways in drought- and low temperature-responsive gene expression, respectively, in Arabidopsis. Plant Cell 10: 13911406.

Meshi, T. and Iwabuchi, M. 1995. Plant transcription factors. Plant Cell. Physiol. 36: 1405-1420.

Mohapatra, S.S., Wolfraim, L., Poole, R.J., and Dhindsa, R.S. 1989. Molecular cloning and relationship to freezing tolerance of cold-acclimation-specific genes of alfalfa. Plant Physiol. 89: 375-380.

Ohta, M., Ohme-Takagi, M., and Shinshi, H. 2000. Three ethylene-responsive transcription factors in tobacco with distinct transactivation functions. Plant J. 22: 29-38.

Ohta, M., Matsui, K., Hiratsu, K., Shinshi, H., and OhmeTakagi, M. 2001. Repression domains of class II ERF transcriptional repressors share an essential motif for active repression. Plant Cell 13: 1959-1968.

Purugganan, M.D. and Wessler, S.R. 1994. Molecular evolution of the plant $R$ regulatory gene family. Genetics 138: 849854.

Shinwari, Z.K., Nakashima, K., Miura, S., Kasuga, M., Seki, M., Yamaguchi-Shinozaki, K., and Shinozaki, K. 1998. An Arabidopsis gene family encoding DRE/CRT binding proteins involved in low-temperature-responsive gene expression. Biochem. Biophys. Res. Commun. 250: 161-170.

Spelt, C., Quattrocchio, F., Mol, J.N.M., and Koes, R. 2000. Anthocyanin1 of petunia encodes a basic-helix-loop-helix protein that directly activates transcription of structural anthocyanin genes. Plant Cell 12: 1619-1631.

Stockinger, E.J. Gilmour, S.J., and Thomashow, M.F. 1997. Arabidopsis thaliana CBF1 encodes an AP2 domain-containing transcription activator that binds to the C-repeat/DRE, a cisacting DNA regulatory element that stimulates transcription in response to low temperature and water deficit. Proc. Natl. Acad. Sci. 94: 1035-1040.

Tahtiharju, S. and Palva, T. 2001. Antisense inhibition of protein phosphatase $2 \mathrm{C}$ accelerates cold acclimation in Arabidopsis thaliana. Plant J. 26: 461-470.

Thomashow, M.F. 1999. Plant cold acclimation, freezing tolerance genes and regulatory mechanisms. Annu. Rev. Plant Physiol. Plant Mol. Biol. 50: 571-599.

Walker, A.R., Davison, P.A., Bolognesi-Winfield, A.C., James, C.M., Srinivasan, N., Blundell, T.L., Esch, J.J., Marks, M.D., and Gray, J.C. 1999. The TRANSPARENT TESTA GLABRA1 locus, which regulates trichome differentiation and anthocyanin biosynthesis in Arabidopsis, encodes a WD40-repeat protein. Plant Cell 11: 1337-1349.

Xin, Z. and Browse, J. 1998. eskimo1 mutants of Arabidopsis are constitutively freezing-tolerant. Proc. Natl. Acad. Sci. 95: 7799-7804.

Yamaguchi-Shinozaki, K., and Shinozaki, K. 1994. A novel cisacting element in an Arabidopsis gene is involved in responsiveness to drought, low-temperature, or high-salt stress. Plant Cell 6: 251-264. 


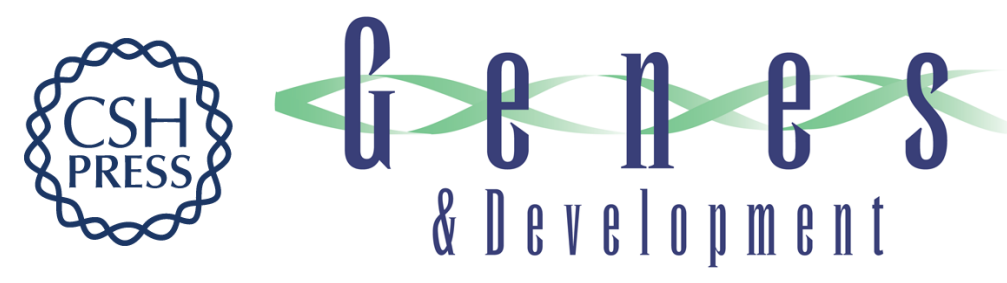

\section{ICE1: a regulator of cold-induced transcriptome and freezing tolerance in Arabidopsis}

Viswanathan Chinnusamy, Masaru Ohta, Siddhartha Kanrar, et al.

Genes Dev. 2003, 17:

Access the most recent version at doi:10.1101/gad.1077503

\section{Supplemental http://genesdev.cshlp.org/content/suppl/2003/04/25/U-10775R.DC1 Material}

References This article cites 35 articles, 22 of which can be accessed free at: http://genesdev.cshlp.org/content/17/8/1043.full.html\#ref-list-1

\section{License}

Email Alerting

Service

Receive free email alerts when new articles cite this article - sign up in the box at the top right corner of the article or click here.

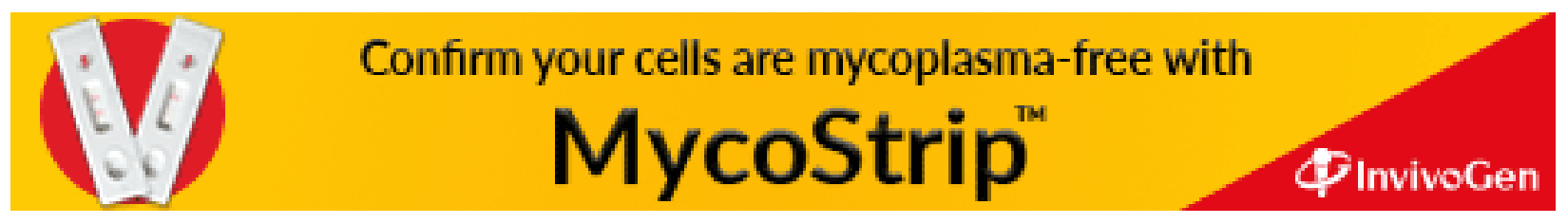

